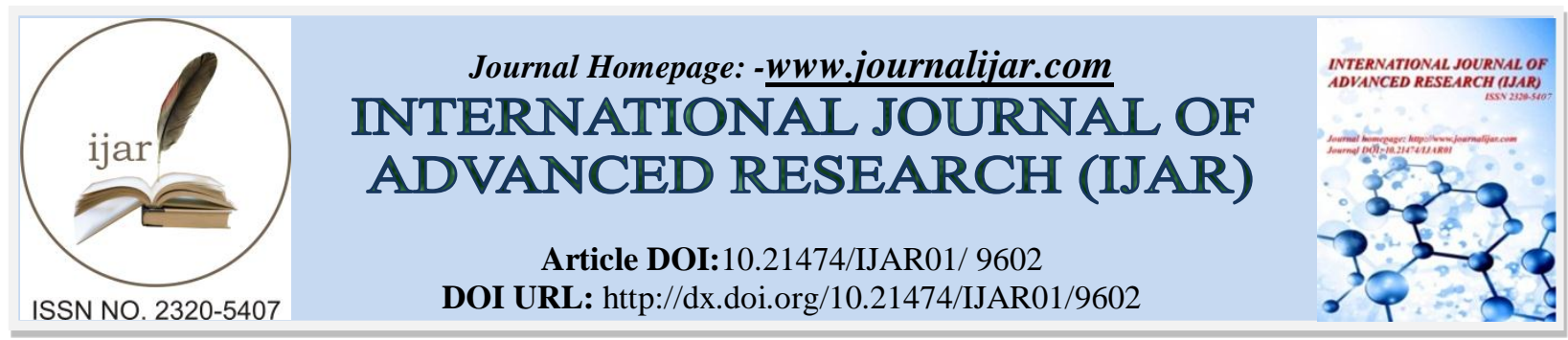

RESEARCH ARTICLE

\title{
SIMPLE HIGH PERFORMANCE LIQUID CHROMATOGRAPHIC METHOD FOR DETERMINATION OF ENANTIOMER OF D-SERINE API.
}

\section{Rajendra Phadke ${ }^{1}$, Dr. Amit Gosar ${ }^{2}$, Narendra Aarkashi ${ }^{2}$, Deepesh Patil ${ }^{2}$ And Rupali Mali ${ }^{2}$.}

1. Research Scholar, J.J.T University, churu, Jhunjhunu Road, Rajasthan -333001.

2. Indoco Remedies Limited, Analytical research \& development department, Navi Mumbai, 400701, Maharashtra, India.

\section{Manuscript Info}

\section{Manuscript History}

Received: 20 June 2019

Final Accepted: 22 July 2019

Published: August 2019

Key words:-

D- Serine, L- Serine, Marfey's reagent,

HPLC, Optical isomers.

\begin{abstract}
Several amino acids have a chiral center and thus can exist as D- and Lisomers. Amino acid synthesis like D-Serine, L-Serine is use as starting material therefore unreacted L-Serine may present in sample. This LSerine is an optical enantiomer of D-serine hence this enantiomer need to be quantified. Thus author has developed simple, sensitive, precise, and specific HPLC method for the separation of L-enantiomer of DSerine using Agilent zorbax SB-C18, $150 \mathrm{~mm}$ x $4.6 \mathrm{~mm}, 3.5 \mu \mathrm{m}$ HPLC column. The mobile phase used as $10 \mathrm{mM}$ Tris buffer with $\mathrm{pH} 3.0 \pm$ 0.05 and Methanol with gradient ratio. D-Serine structure there was no any chromophore are observed therefore author was derivatised the sample with the Marfey's reagent and further validated the method as per ICH Q2 (R1) guideline and same method can be used for routine analysis.
\end{abstract}

Copy Right, IJAR, 2019,. All rights reserved.

\section{Introduction:-}

D-Serine is a non-essential amino acid and dextro isomer of serine with antipsychotic activity. D-serine is a selective full agonist at the glycine site of N-methyl-D-aspartate (NMDA)-type glutamate receptor. Hypo function of NMDA type of neuro transmission is believed to play a major role in pathophysiology of schizophrenia, therefore, administration of D-serine and subsequent activation of NMDA receptors may alleviate psychotic tendencies. The enzymes involved in its formation and catabolism are serine racemase (SR) and D-amino acid oxidase (DAAO), respectively, and manipulations of the activity of those enzymes have been useful in developing animal models of schizophrenia and in providing clues to the development of potential new antipsychotic strategies. $\mathrm{D}$-serine is the R-enantiomer of serine. It has a role as a NMDA receptor agonist, a human metabolite and an Escherichia coli metabolite. It is a D-alpha-amino acid and a serine. It is a conjugate base of a D-serinium. It is a conjugate acid of a D-serinate. It is an enantiomer of an L-serine. It is a tautomer of a D-serine zwitterion.

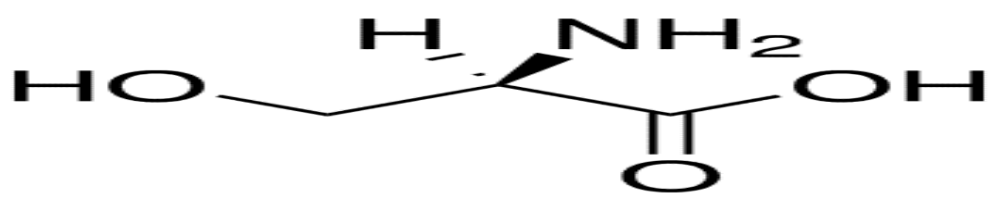

Fig 01:- D-Serine [(2R)-2-amino-3-hydroxypropanoic acid]

Corresponding Author:-Rajendra Phadke.

Address:-Research Scholar, J.J.T University, churu, Jhunjhunu Road, Rajasthan -333001. 
D-Serine is used as starting material for Lacosamide synthesis; hence, to show the absence of D-serine in an intermediate up to trace level is important. D-serine has an enantiomer, if this enantiomer is higher or more than specified limit than final finished product may fails for optical purity test, therefore this enantiomer should be control in their starting material. D-serine structure has no chromophore hence difficult to analyze by routine HPLC, whereas D-serine is insoluble in most of the polar and non-polar solvents and highly soluble in water therefore we cannot inject water solution in Gas chromatogram. The author has developed the new technique as derivatizating method. The column used for development was Agilent zorbax SB-C18, $150 \mathrm{~mm}$ x $4.6 \mathrm{~mm}, 3.5 \mu \mathrm{m}$ and mobile phase used as $10 \mathrm{mM}$ Tris buffer with $\mathrm{pH} 3.0 \pm 0.05$ and Methanol with gradient ratio. The reagent used for derivatizating was Marfey's reagent. This method has detect and quantify unwanted enantiomer up to $1 \mathrm{ppm}$ level in the D-Serine. The purpose of the present research work is to develop a suitable derivative HPLC method for the determination and quantification of L- serine in the D-serine substance with an established limit of 1 ppm. The developed HPLC method was validated with respect to specificity, LOD, LOQ, linearity, precision and accuracy. These studies are performed in accordance with established International Conference on Harmonization (ICH) guidelines.

\begin{tabular}{|c|c|c|}
\hline Sr. No. & Chemical Name & Structure \\
\hline 1 & L-Serine & L \\
\hline
\end{tabular}

Table 1:-Chemical Name And Structure Of D-Serine Related Enantiomer

\section{Materials:-}

\section{Reagent and Chemicals.}

D-serine, L-Serine working standard and Raw material were received from Analytical research and development department of Indoco Research Centre (Navi Mumbai). HPLC grade Tris (hydroxy methyl) aminomethane Buffer, orthophosphoric acid, No-(2,4-Dinitro-5-fluorophenyl)-L-alaninamide [Marfey's Reagent], Acetone, Sodium bicarbonate AR grade and $1 \mathrm{~N}$ Hydrochloric acid solution were purchased from Merck (India).

\section{Instrumentation.}

Waters, Alliance 2695 series HPLC system comprising a quaternary pump, an autosampler, a thermostatic column compartment, a solvent cabinet with degasser along with photodiode array (PDA) 2998 and ultraviolet (UV) 2487 detectors were used for separation and detection. Data acquisition and calculations were carried out using Waters Empower3 software (Milford). Sartorius (Germany) analytical balance was used for weighing material.

\section{Methodology:- \\ Preparation of Mobile Phase \\ Buffer Preparation:}

Transfer $1.21 \mathrm{~g}$ of Tris (hydroxy methyl) aminomethane Buffer into 1L bottle, containing $1000 \mathrm{~mL}$ of water, dissolve and shake well. Adjust the $\mathrm{pH}$ of solution to $3.0 \pm 0.05$ with ortho phosphoric acid. Filter the solution through a $0.45 \mu \mathrm{m}$ membrane filter and degas by sonication for 2 minutes.

\section{Mobile Phase-A}

Use buffer preparation as mobile phase A.

\section{Mobile Phase-B}

Methanol

\section{Diluent}

Water

\section{Preparation of Marfey's Reagent:}

Add $20 \mathrm{mg}$ of $\mathrm{N \alpha}$-(2, 4-Dinitro-5-fluorophenyl)-L-alaninamide [Marfey's Reagent] in 20ml volumetric flask dissolve reagent in $5 \mathrm{ml}$ acetone. Make up volume with Acetone. 


\section{Preparation of Blank:}

Mix $2 \mathrm{ml}$ water, $2 \mathrm{ml}$ Sodium bicarbonate and $3 \mathrm{ml}$ Marfey's Reagent in $10 \mathrm{ml}$ volumetric flask keep reaction mixture for $1 \mathrm{hrs}$ at $40^{\circ} \mathrm{C}$. After $1 \mathrm{hrs}$ add $1 \mathrm{ml} 1 \mathrm{~N} \mathrm{HCL}$ and makeup volume with diluent.

Preparation of solutions:

System suitability solution:

Add 20mg of L-Serine and 20mg of D-Serine in $100 \mathrm{ml}$ volumetric flask make up the volume with diluent.

Transfer $1 \mathrm{ml}$ of above solution in $100 \mathrm{ml}$ volumetric flask make up the volume with diluent.

\section{Preparation of System suitability solution:}

Mix $2 \mathrm{ml}$ above solution, $2 \mathrm{ml}$ Sodium bicarbonate and 3ml Marfey's Reagent in 10ml volumetric flask keep reaction mixture for $1 \mathrm{hrs}$ at $40^{\circ} \mathrm{C}$. After $1 \mathrm{hrs}$ add $1 \mathrm{ml} 1 \mathrm{~N} \mathrm{HCL}$ and makeup volume with diluent.

\section{Reference solution:}

Add $20 \mathrm{mg}$ of D-Serine in $100 \mathrm{ml}$ volumetric flask, dissolve in $50 \mathrm{ml}$ of diluent, makeup volume to $100 \mathrm{ml}$ with diluent.

Take $1 \mathrm{ml}$ of above solution in $100 \mathrm{ml}$ of volumetric flask, makeup volume to $100 \mathrm{ml}$ with diluent.

\section{Preparation of Reference solution:}

Mix $2 \mathrm{ml}$ above solution, $2 \mathrm{ml}$ Sodium bicarbonate and 3ml Marfey's Reagent in 10ml volumetric flask keep reaction mixture for $1 \mathrm{hrs}$ at $40^{\circ} \mathrm{C}$. After $1 \mathrm{hrs}$ add $1 \mathrm{ml} 1 \mathrm{~N} \mathrm{HCL}$ and makeup volume with diluent.

\section{Test solution:}

Take $20 \mathrm{mg}$ of sample in $20 \mathrm{ml}$ volumetric flask, dissolve in $5 \mathrm{ml}$ of diluent make up the volume with diluent. $2 \mathrm{ml}$ of above test solution, $2 \mathrm{ml}$ Sodium bicarbonate and 3ml Marfey's Reagent in 10ml volumetric flask keep reaction mixture for $1 \mathrm{hrs}$ at $40^{\circ} \mathrm{C}$. After $1 \mathrm{hrs}$ add $1 \mathrm{ml} 1 \mathrm{~N} \mathrm{HCL}$ and makeup volume with diluent.

\section{Chromatographic Conditions}

\begin{tabular}{|c|c|c|c|}
\hline Column & \multicolumn{3}{|c|}{ Agilent zorbax SB-C18, $150 \mathrm{~mm} \times 4.6 \mathrm{~mm}, 3.5 \mu \mathrm{m}$ or equivalent } \\
\hline Column Temperature & \multicolumn{3}{|c|}{$25^{\circ} \mathrm{C}+2^{\circ} \mathrm{C}$} \\
\hline Flow Rate & \multicolumn{3}{|l|}{$1.2 \mathrm{~mL} / \mathrm{min}$} \\
\hline \multirow[t]{9}{*}{ Gradient program } & Time (min) & Mobile Phase-A (\%) & Mobile Phase-B (\%) \\
\hline & 0 & 85 & 15 \\
\hline & 4 & 85 & 15 \\
\hline & 15 & 75 & 25 \\
\hline & 26 & 75 & 25 \\
\hline & 30 & 30 & 70 \\
\hline & 35 & 30 & 70 \\
\hline & 40 & 85 & 15 \\
\hline & 45 & 85 & 15 \\
\hline Injection Volume & \multicolumn{3}{|l|}{$50 \mu \mathrm{L}$} \\
\hline Detector Wavelength & \multicolumn{3}{|l|}{$340 \mathrm{~nm}$} \\
\hline Run Time & \multicolumn{3}{|l|}{45 minutes } \\
\hline Retention Time & \multicolumn{3}{|c|}{ D-Serine is about 20 minutes } \\
\hline Needle wash & \multicolumn{3}{|c|}{ Methanol: Water (50:50) } \\
\hline
\end{tabular}

Table 2:-Chromatographic Conditions

Injection sequence:

\begin{tabular}{|c|l|c|}
\hline Sl\# & \multicolumn{1}{|c|}{ Description } & No. of Injections \\
\hline 1 & Blank & 1 \\
\hline 2 & System suitability solution & 1 \\
\hline
\end{tabular}




\begin{tabular}{|c|l|c|}
\hline 3 & Blank & 1 \\
\hline 4 & Test solution & 1 \\
\hline
\end{tabular}

Table 3:-Injection sequence

\section{Procedure:}

Equilibrate the HPLC system with the initial composition until a steady baseline is obtained. Inject blank and system suitability and ensure that system suitability parameters meet the requirements. Inject blank and test solution as per injection sequence into the chromatograph and record the chromatograms.

\begin{tabular}{|l|l|l|}
\hline Sl\# & Name & RRT \\
\hline 1 & D-Serine & 1.00 \\
\hline 2 & L-Serine & 0.85 \\
\hline
\end{tabular}

Table 4:-Rrt

\section{System suitability:}

Acceptance criteria

\section{Resolution:}

The resolution between peak due to D-Serine and L-Serine should not be less than 2.0 in the chromatogram obtained with system suitability solution.

\section{Tailing factor:}

The tailing factor for peak due to D-Serine in System suitability solution should not be more than 3.0.

\section{Calculation}

Calculate the content of L-Serine as enantiomer in area normalization technique.

\section{Analytical Method Validation}

The aim of the present study was to develop and validate analytical methods for the estimation of L-serine in Dserine by using HPLC. The developed method is subjected to analytical method validation, which is conducted according to the International council for Harmonisation (ICH) guidelines. The parameter which was taken for analytical method validation was specificity, limit of detection, limit of quantitation, linearity, accuracy, precision, robustness and stability of solution.

Method validation was performed on HPLC analysis, in order to evaluate which chromatographic technique might be more suitable for application to real samples. Target analytes were identified in the chromatograms by comparison of the retention time of the peaks obtained with these ones of a standard solution. Simultaneously the identification of the analytes was also confirmed comparing the corresponding UV spectra of the peaks of the sample and of standard solution chromatograms

\section{Results And Discussion:-}

\section{System suitability}

The System suitability test is mainly applied to determine the column efficiency, resolution, and repeatability of a particular chromatographic system to verify its ability for a defined analysis. To check the system suitability, system suitability solution was injected and observed the resolution between D- serine peak and L-serine peak, then further injected three replicate injections of reference solution as low load of D- serine and calculate percent relative standard deviation for the D-serine peak. The details area of reference solution, relative standard deviation and resolution were recorded in Table 5. The percent relative standard deviation should be less than 2.0 and resolution should not be less than 2.0 in D- serine and L-serine peak, the system suitability was checked before each validation parameter. The details of data are as follows

\begin{tabular}{|c|c|c|}
\hline Name & No of Injection & Area \\
\hline Reference Solution & Injection-1 & 260561 \\
\cline { 2 - 3 } & Injection-2 & 256768 \\
\cline { 2 - 3 } & Injection-3 & 260105 \\
\cline { 2 - 3 } & Avg. Area & 259145 \\
\hline
\end{tabular}




\begin{tabular}{|c|c|c|}
\hline & Std. Deviation & 2070.92 \\
\hline & $\%$ RSD & 0.80 \\
\hline Theoretical plate & \multicolumn{2}{|c|}{39790} \\
\hline Resolution between D- serine and L- serine & \multicolumn{2}{|c|}{6.81} \\
\hline
\end{tabular}

Table 5:-System suitability data

\section{Specificity}

The specificity of the method was ascertained by analyzing the standards and the samples. The Test sample solutions and spiked sample solution were prepared as per specification limit and injected into the HPLC system. The retention time of all peaks observed in the resulting chromatograms were recorded. Based on the obtained result it is concluded that no interference observed due to blank at the same retention time of the L-serine and main peak. The peak purity of D- serine and L-serine peak are pure and passes as acceptance limit.

Figure 2 shows the typical chromatograms of the blank solution, system suitability solution, reference solution (a), Test solution and impurities spiked test sample. The results indicated that L-serine is well separated under the current chromatographic conditions. Also, there was no interference of peaks from the blank solution and the samples solution within the retention time of L-serine and D-serine peak. The Peak purity for L-serine and D-serine peak were passing as per acceptance criteria. The retention times of L-serine, D-serine and peak purity refer Table No.06.

\begin{tabular}{|l|l|l|l|l|l|l|}
\hline Sr.No & Peak Name & RT & Area & $\begin{array}{l}\text { RT } \\
\text { Ratio }\end{array}$ & Purity angle & $\begin{array}{l}\text { Purity } \\
\text { threshold }\end{array}$ \\
\hline 1 & L-serine & 18.09 & 277219 & 0.85 & 0.26 & 0.29 \\
\hline 2 & D-serine & 20.62 & 14177183 & 1.00 & 0.04 & 0.25 \\
\hline
\end{tabular}

Table 06:-Peak Purity For Spiked Test Solution

Figure. 2:-Specificity Typical chromatogram

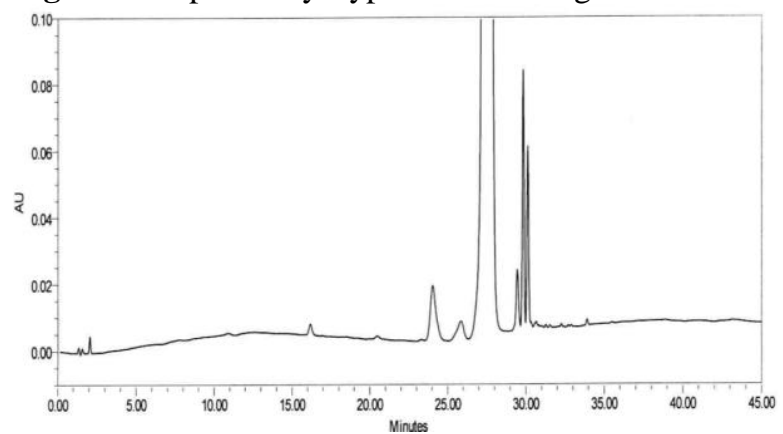

(A)

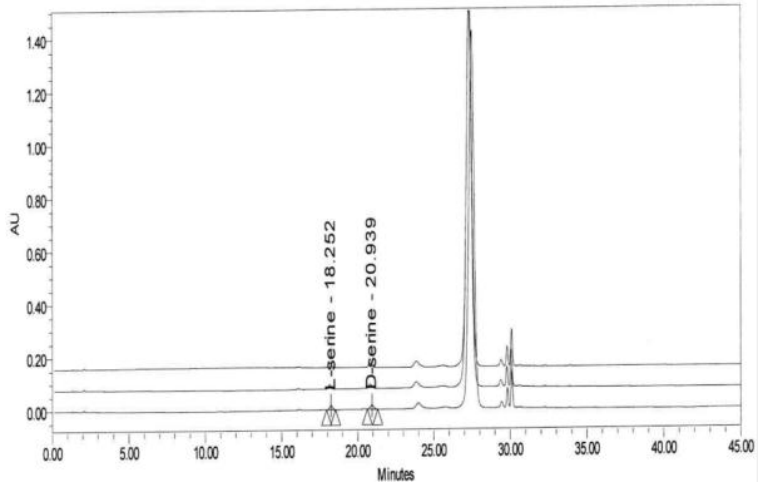

(C)

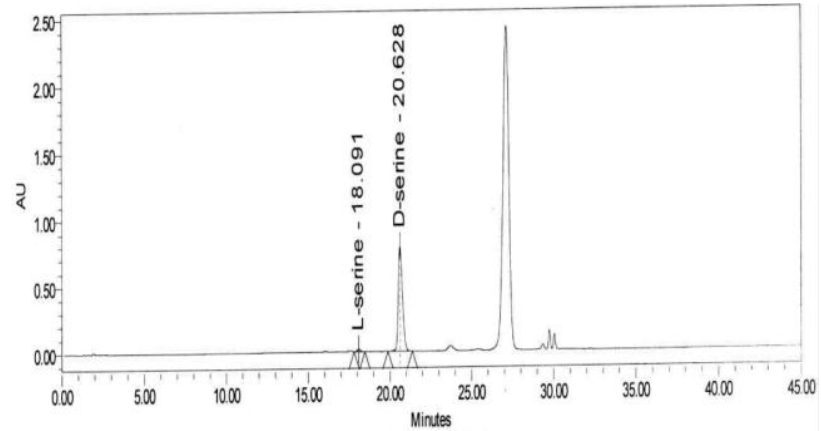

(B)

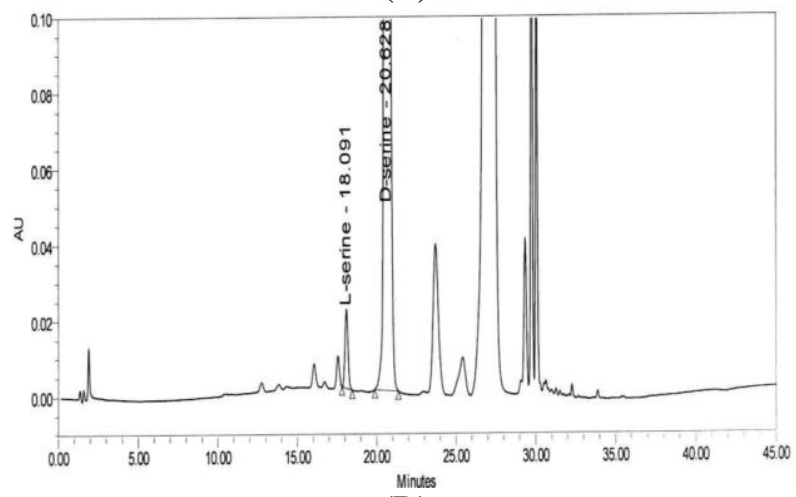

(D)

A) Blank, B) System Suitability Solution, C) Reference Solution (A) D) D-Serine Spiked Sample 


\section{Limit of detection and limit of quantitation}

A series of standard solutions of D-Serine and its enantiomer were prepared and injected in concentration ranging from $25 \%$ to $150 \%$ of target concentration. Limit of detection (LOD) and Limit of quantitation (LOQ) was calculated based on standard deviation (STEYX) of regression line and slope. The calculated LOD and LOQ was well within limit as per ICH guideline and it shown below 0.04 LOD and 0.15 ppm LOQ for L-Serine and D-Serine also (Table 07).

\begin{tabular}{|l|l|l|l|}
\hline Sr. No & Name of impurities & \multicolumn{2}{|c|}{ Parameter } \\
\cline { 3 - 4 } & & LOD & LOQ \\
\hline 1 & D-Serine & 0.05 & 0.15 \\
\hline 2 & L-Serine & 0.04 & 0.13 \\
\hline
\end{tabular}

Table 07:-Limit of detection and quantitation

\section{Linearity}

The linearity of the method was established by setting calibration curves using linear regression analysis over the concentration range of $25 \%, 75 \%, 100 \%, 125 \%$, and 150\%; however final concentrations tested depend of the sensitivity reached for each analyte. The linearity curves were drawn by plotting the peak response of D-Serine and L-Serine against its corresponding concentration of linearity solution. Regression coefficient, slope and \% y intercept are calculate and reported in Table 8. Observed regression coefficient was greater than 0.99 and $\% \mathrm{y}$ intercept was less than $27 \%$.

\section{D-serine}

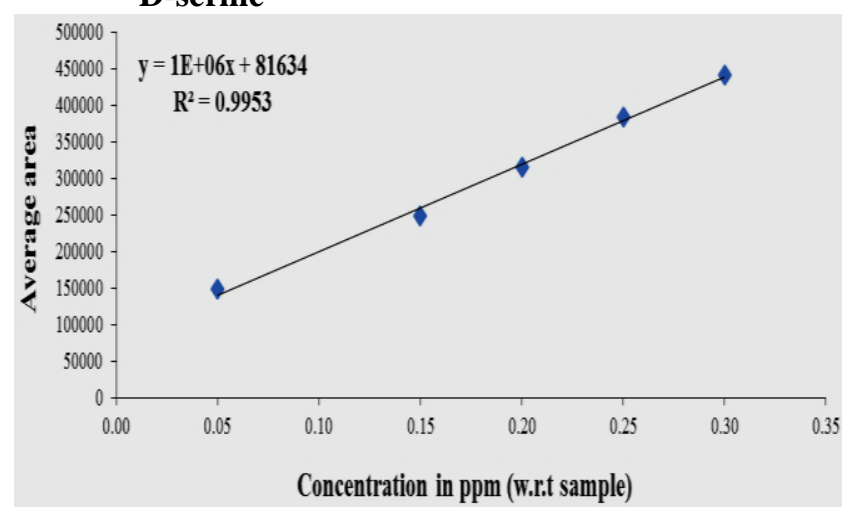

Slope

Intercept

$\%$ y-Intercept

Regression coefficient $\left(\mathrm{R}^{2}\right)$
594254.32

81633.76

25.90

0.9953

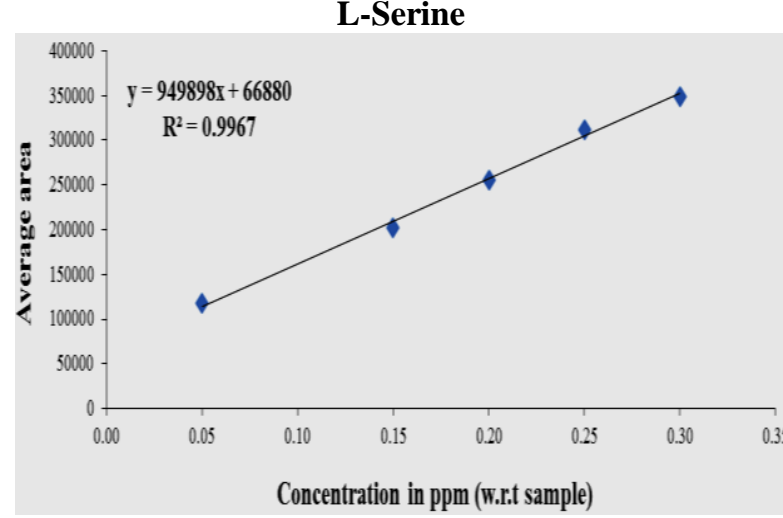

Slope

Intercept

$\%$ y-Intercept

Regression coefficient $\left(\mathrm{R}^{2}\right)$
474949.05

66879.96

26.14

0.9967

Table 08:-Linearity table and figure

\section{Precision}

System precision was carried out by analyzing three reference solutions of D-Serine at a limit level concentration. Relative standard deviation for the peak area of D-Serine was calculated and found to be $0.80 \%$ Precision at LOQ was calculated by preparing impurities mixture at LOQ concentration and injecting three times. Relative standard deviation for impurities peaks where below $1.08 \%$ (Table 09).

\begin{tabular}{|c|l|c|}
\hline Parameter & \multicolumn{1}{|c|}{ Peak name } & \% RSD for peak area \\
\hline System precision & D-Serine & $0.80 \%$ \\
\hline Precision at LOQ & All the impurities & $1.08 \%$ \\
\hline
\end{tabular}

Table 09:-System precision and precision at loq 


\section{Accuracy}

Method accuracy (expressed as recovery percentage) were evaluated by recovery studies of the analytes in sample, spiked at different final concentration levels. The accuracy of method was demonstrated by injecting the standard at $50 \%, 100 \%$ and $150 \%$ level with respect to analyte concentration. Accuracy solution was prepared at each level and injected each preparation into chromatographic system. Recoveries were determined comparing the concentrations obtained with the initial spiking levels. Each spiked test solution was analyzed for recovery study and observe the percentage recovery. Recovery obtained for L-Serine should between $88 \%$ to 105\% (Table-10, 11 and 12).

\begin{tabular}{|l|l|c|c|c|c|c|}
\hline $\begin{array}{l}\text { Sr. } \\
\text { No. }\end{array}$ & Imp Name & $\begin{array}{c}\text { Test } \\
\text { Area }\end{array}$ & $\begin{array}{c}\text { Observed } \\
\text { Area }\end{array}$ & $\begin{array}{c}\text { Theoretical } \\
\text { Added } \\
\text { Imp (\%) }\end{array}$ & $\begin{array}{c}\text { Observed } \\
\text { Imp (\%) }\end{array}$ & $\begin{array}{c}\text { Recovery } \\
(\boldsymbol{\%})\end{array}$ \\
\hline 1 & L-Serine & 696 & 117085 & 0.10 & 0.11 & 104.33 \\
\hline
\end{tabular}

Table 10:-Recovery of impurities- 50\%

\begin{tabular}{|c|l|c|c|c|c|c|}
\hline $\begin{array}{l}\text { Sr. } \\
\text { No. }\end{array}$ & Imp Name & $\begin{array}{c}\text { Test } \\
\text { Area }\end{array}$ & $\begin{array}{c}\text { Observed } \\
\text { Area }\end{array}$ & $\begin{array}{c}\text { Theoretical } \\
\text { Added } \\
\text { Imp (\%) }\end{array}$ & $\begin{array}{c}\text { Observed } \\
\text { Imp (\%) }\end{array}$ & $\begin{array}{c}\text { Recovery } \\
(\boldsymbol{\%})\end{array}$ \\
\hline 1 & L-Serine & 696 & 220010 & 0.20 & 0.20 & 98.30 \\
\hline
\end{tabular}

Table 11:-Recovery of impurities- 100\%

\begin{tabular}{|c|l|c|c|c|c|c|}
\hline $\begin{array}{l}\text { Sr. } \\
\text { No. }\end{array}$ & Imp Name & $\begin{array}{c}\text { Test } \\
\text { Area }\end{array}$ & $\begin{array}{c}\text { Observed } \\
\text { Area }\end{array}$ & $\begin{array}{c}\text { Theoretical } \\
\text { Added } \\
\text { Imp (\%) }\end{array}$ & $\begin{array}{c}\text { Observed } \\
\text { Imp (\%) }\end{array}$ & $\begin{array}{c}\text { Recovery } \\
(\boldsymbol{\%})\end{array}$ \\
\hline 1 & L-Serine & 696 & 295191 & 0.30 & 0.26 & 88.00 \\
\hline
\end{tabular}

Table 12:-Recovery of impurities- $150 \%$

Solution stability

Test solution stability was established by injecting the test solution after every six hours' time interval up to 24 hours. The result obtained is well within specified limit with and relative standard deviation should be less than 5.0 $\%$, thus solution stability was established up to 24 hours at $25^{\circ} \mathrm{C}$ (Table 13).

\begin{tabular}{|l|l|c|c|c|c|}
\hline \multirow{2}{*}{ Sr. No. } & \multirow{2}{*}{ Chiral Content } & \multicolumn{4}{|c|}{ Content in \% } \\
\cline { 3 - 5 } & & $6 \mathrm{Hrs}$ & $12 \mathrm{Hrs}$ & $18 \mathrm{Hrs}$ & $24 \mathrm{Hrs}$ \\
\hline 1 & L-Serine & Not detected & Not detected & Not detected & Not detected \\
\hline
\end{tabular}

Table 13:-Solution stability of d-serine

\section{Conclusion:-}

The proposed methods were found to be simple and rapid for determination of L-Serine content in D-Serine. This is the first precise and accurate HPLC method has been developed and successfully validated for the monitoring of optical isomers in D-Serine. The results of the HPLC validation tests indicated that the method was accurate, precise and reproducible. The system suitability parameters were within limit, hence it was concluded that the proposed HPLC method is suitable for routine analysis of D-Serine.

\section{Acknowledgement:-}

The author wishes to thank to the management of Indoco Remedies Limited for supporting this work by providing the samples of D-Serine as raw material and Impurities working standard required for this research.

\section{References:-}

1. Herman Wolosker et al; D-Amino acids in the brain; D-Serine in neurotransmission and neurode generation; The Febs Journal; 2008, 275 (14), 3514-3526.

2. Valarmathi R et al; Simple UV spectrophotometric method development and validation for determination of Lacosamide in bulk and its tablet dosage form; International Journal of Pharmaceutical and Chemical Sciences; 2013, 5(1), 373-376.

3. Nageswara Rao ABN, et al; UV-Visible spectrophotometric method for the determination of Lacosamide in its pure and tablet dosage form; Der Pharmacia Lettre; 2012, 4 (6), 1737-1741. 
4. Rajeshri D. Chaudhari, et al; Development and validation of first order derivative spectrophotometric method for estimation of Lacosamide in bulk and tablet dosage form; Asian journal of pharmaceutical and clinical research; 2013, 6(3), 162-164.

5. Sachin Shah, et al; Development and validation of stability-indicating assay method for Lacosamide by RPHPLC; Elixir Pharmacy; 2011, 38, 4174-4177.

6. International conference on harmonization, November, 2005, Validation of analytical procedures :Text andMethodologyQ2(R1)USP, United States Pharmacopoeia, Validation of Compendial Methods, $31^{\text {st }}$ Edition, United States Pharmacopeial Convention, Rockville, (2008).

7. ICH guidelines. Validation of analytical procedures, test and methodology Q2 (R1) November 2003.

8. ICH specifications. Test procedures and acceptance criteria for new drug substances and drug products: Chemical substances. International conference on Harmonisation. IFPMA, Geneva, 1999.

9. C. B'Hymer, et al; Marfey's reagent: Past, present, and future uses of 1-fluoro-2, 4-dinitrophenyl-5-L-alanine amide. J. Sep. Sci. 26: 7-19 (2003).

10. Mothet JP, et al; D-serine is an endogenous ligand for the glycine site of the N-methyl-D-aspartate receptor. Proceedings of the National Academy of Sciences. 2000 Apr 25; 97 (9):4926-31. 